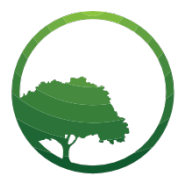

Research in Business \& Social Science

IJRBS VOL 8 NO 5 ISSN: 2147-4478

\title{
Health providers' perspective of effect of copayment on delivery of effective health service under capitation in Kenya
}

\author{
Priscilla Wangai ${ }^{a *}$, Amos Njuguna ${ }^{b}$, Joseph Ngugic \\ ${ }^{a, b, c}$ Chandaria School of Business, United States International University-Africa, Nairobi, Kenya
}

Crossref

\begin{tabular}{l} 
A R T I C L E IN F O \\
\hline Article history: \\
Received 30 July 19 \\
Received in revised form 15 July 19 \\
Accepted 16 August 19 \\
\hline Keywords: \\
Copayment \\
Capitation \\
Quality \\
Accessibility \\
Affordability \\
Kenya \\
JEL Classification: \\
O15 \\
P36
\end{tabular}

\begin{abstract}
A B S T R A C T
Co-payment is an out-of-pocket payment collected by the service provider from members capitated by a health scheme for the purpose of gatekeeping against the misuse of the services. This paper documents an assessment of the effect of copayment on the effectiveness of health services delivered under the capitation scheme in Kenya. The unit of analysis was the 1152 health facilities capitated by the National Hospital Insurance Fund to provide outpatient primary healthcare in Kenya as of July 2015. logit regression was used to analyze the data collected from a sample of 297 capitated health facilities. The Effectiveness of the delivery of health services was evaluated using three metrics; quality, accessibility, and affordability. The regression model for each of the metrics was constructed in order to examine the effect of copayment on the delivery of services. The results revealed that an increment of one unit on copayment increased the index of delivery of quality, accessible and affordable health services by $.073,4.349$ and 79.4 respectively. The optimal amount of copayment is determined from the models using theories of calculus.
\end{abstract}

\section{Introduction}

Co-payment is a common practice in financing health services in most economies (Kipp, et al., 2001). Though the payment is often a small fraction of the actual cost of the health services provided, the underlying philosophy is to reduce unnecessary utilization of resources (Varela \& Timofte, 2011). However, in the developing economies, the rich secure insurance cover from private insurance firms whereas the poor pay for healthcare services out-of pocket (Hooda, 2017). In Pakistan healthcare expenditure is approximately US $\$ 17$ per head per year, out of which $\$ 13$ is out-of-pocket expenditure. The country spends $15 \%$ of its health budget on primary health care services which is utilized by $80 \%$ of the population (Hunte \& Sultana, 1992). In India, more than $70 \%$ of total health expenditures are financed through copayment, though most of the out-of-pocket spending is for inpatient services. Under the National Rural Health Mission, free treatment in public hospitals is extended to maternity, newborn, and infant care and on control of tuberculosis, malaria, and HIV/ AIDS (Balarajan, Selvaraj, \& Subramanian, 2011). For all other services, copayments continue to apply, especially for diagnostics tests and drugs which are excluded from the state's essential drug list. Citizens in majority of the African economies finance healthcare services through; individual out-of-pocket payments, employer payment, national social health insurance cover or through private insurance. On average the total health expenditure in African countries stood at US\$135 per capita in 2010, which is only a small fraction of the US $\$ 3150$ spent on health by high-income countries (WHO, 2010). In order to realize the universal coverage with access to quality and affordable healthcare, majority of the African countries have initiated national health insurance schemes in their health service delivery. Similar to the models of the developed economies, most of these schemes

\footnotetext{
* Corresponding author. Tel: +254-722489282 ORCID ID: 0000-0002-1883-2732

Peer review under responsibility of Bussecon International Academy.

(C) 2019 Bussecon International. Hosting by SSBFNET- Center for Strategic Studies in Business \& Finance. All rights reserved.

https://doi.org/10.20525/ijrbs.v8i5.460
} 
have an element of capitation contracting either in whole or part (Ataguba \& Akazili, 2010; Kipyegon \& Nyarombe, 2015; Saksena, \& Antunes, 2011).

Capitation is a prospective healthcare financing scheme and is said to be the oldest form of financing primary health care. It involves paying a health provider a predetermined amount for each person enrolled with them over a specified period of time, whether or not that person seeks care (Allard, Jelovac, \& Léger, 2014). Some capitation payment schemes have a blended model which incorporates risk adjustment for some conditions. The payable rates are therefore calculated based on the average expected utilization of healthcare for the specific condition (Horowitz, 1997; Files \& Murray, 1995). In some cases, co-payments are allowed. Nevertheless, copayment can act as a barrier to access medical services by needy patients hence rendering someone who is insured effectively uninsured due to their inability to pay the predetermined copayment (Goldman, Joyce \& Zheng, 2007). However, omission of imposing it exposes the fund to gross misuse and excessive demands of treatments by the capitated members. To the contrary, Chen, Schafheutle, and Res (2009) argued that copayment imposed to members of a health insurance scheme places a financial burden to the insured members resulting to decrease in utilization of the procured health services. For healthcare providers to deliver effective health services under capitation scheme, an optimal point should be determined that is high enough to prevent unnecessary utilization of healthcare resources but low enough to enable access to healthcare by the needy insured members. There is therefore need to develop a model that examines the effect of copayment on the delivery of effective health services in terms of its quality, accessibility and affordability. This is the motivation of this research work.

\section{Literature Review}

This study is anchored on the Incentive contracting theory which explicates the contractual relationship between the healthcare providers, health plan beneficiaries and the insurer of the capitation payment scheme (Fama, 1980; Purkayastha, Manolova,\& Edelman, 2012). Under this theory, the assumption of copayment is that reducing unnecessary consultations, appropriate utilization of resources will be achieved. From provider perspective, copayment gives a healthcare provider an incentive to provide affordable, quality and accessible medical services to members capitated to a health plan (Augurzky, et al., 2006).

Previous studies have assessed the impact of copayment on utilization of healthcare resources (Varela \& Timofte, 2011; Augurzky, et al., 2011; Bauer \& Schaffner, 2006). Due to variations in study designs, differences in economic ability and level of healthcare needs among patient population, the results have presented mixed conclusions that make generalization difficult. According to Gravelle and Siciliani (2008), optimal co-payment trades off insurance with the moral hazard. It lies between zero and the full cost of healthcare. This implies that setting a co-payment at zero (no copayment paid) is sub-optimal because it results to patients demanding excessive care. On the other hand, setting co-payment in service delivery equal to the cost of healthcare is also suboptimal because it eliminates insurance cover.

In an attempt to control medical expenditures, the Japanese government increased copayments from $20 \%$ to $30 \%$ for patients covered by the Employee Health Insurance System. To investigate whether this increase barred patients with hypertension and those with diabetes mellitus from receiving necessary healthcare, Babazono, Miyazaki, and Une (2004) conducted a study using 211 patients with hypertension and 66 patients with diabetes mellitus who regularly visited their preferred healthcare providers from October 2001 to March 2002. The results showed that there was no significant change in compliance rate of attendance from patients with hypertension and diabetic patients with complications. However, a significant decrease was observed among diabetic patients without complications. Accordingly the conclusion was that increasing co-payments reduced unnecessary visits by diabetic patients without complications. Further, Shapiro, Ware, and Sherbourne (1986) examined quantitatively the effects of an increase of copayment from $10 \%$ to $20 \%$ on the demand for medical services in Japan. The respondents were employees insured by the 1,797 health insurance companies belonging to the National Federation of Health Insurance Societies. Measurements of demand for medical service included; the inpatient services, outpatient services, dental services and other medical resources utilized per day by insured patients. Taking into account the average age of the patients, the average monthly salary, the gender ratio and the dependent ratio of the insured, the estimated change in all the variables was negative implying, that increase in copayments from $10 \%$ to $20 \%$ resulted to shifting costs from the insurer to the insured consequently there was reduced demand for medical services.

Selby, Fireman and Swain (1996) used a sample of 30,276 respondents whose age ranged between 1 and 63 years to investigate the use of the emergency department in northern California in 1992 and 1993. The purpose of the study was to examine the use of various HMO services and their clinical outcomes before and after introduction of copayment of $\$ 25$ to $\$ 35$. Two randomly selected control groups that were not affected by the copayment were compared with the sampled group. After adjusting the data for, sex, age, and socioeconomic status, the results showed a $14.6 \%$ decline in number of visits to emergency department by the group paying copayments. The decline in use of emergency department was small and not statistically significant for cases that actually needed emergency healthcare however for cases that were classified as "not emergency", the declines were large and statistically significant with the decreasing severity of the conditions. Another study conducted in German by Winkelmann (2004) used the German health care reform of 1997 to examine the impact of copayments for prescribed drugs, which had been increased by $200 \%$ through reform, on physicians' consultation. The researcher employed two different samples and two different econometric models; Sample A. comprising 37,319 observations, an alternative sample B comprising 18,683 observations was used for the purpose of checking the robustness of the results. Poisson model was used to analyze data. The study results revealed that this policy measure decreased the number of physician consultations by $15 \%$. 
There is some evidence that copayment fees exemptions result in increased utilization of health services. Studies by Witter, Dieng, Mbengue, Moreira, and De Brouwere (2010) in Senegal; El-Khoury, Hatt, and Gandaho (2012) in Mali reported an increase in caesarean section operations rates in the respective countries over one-year period after copayment fees were removed. The rate of caesarean section operations in Senegal increased from 4.2 to $5.6 \%$ while in Mali the rate went- up from $0.9 \%$ to $2.3 \%$. In Uganda, Nabyonga, Desmet, Karamagi, Kadama, and Omaswa (2005) examined the effects of the abolition of copayment on utilization of health services with emphasis on poor and vulnerable groups.

A longitudinal study that employed quantitative and qualitative methods was carried out in 106 health facilities across the country to determine trends in overall utilization patterns of health services among these vulnerable groups. The results revealed that there was a marked increase in utilization of health services by all population groups under study. The increase in utilization rose by $55 \%$, $44 \%$ and $77 \%$ between 2000 and 2002, in public referral facilities and the lower level facilities; the district and the community facilities respectively. A study conducted in US by Ciemens (2004) investigated whether reduction of amount paid as copayment increased utilization of outpatient services by a unique group of adolescent who were substance abusers. Using a sample size of 31,585 substance abusers derived from a data base on utilization of mental health and substance abuse services between 1998 and 2001 , data was collected and analyzed using moving-average time-series modeling method. Results revealed that service utilization increased following reduction in copayment amount.

It is evident from the literatures reviewed that copayment presented mixed conclusions that makes generalization difficult. It is also evident that optimal co-payment trades off members continuing receiving medical care under the capitation cover with no copayment charge and the moral hazard behavior. For the purpose of developing optimal copayment that does not hinder member under capitation payment scheme from receiving necessary treatment or on the other hand misuse of the services from excessive unnecessary demand, it is a worth task to assess the effect of imposing copayment on delivery of effective health services from provider perspective.

\section{Research and Methodology}

\section{Research philosophy}

The researcher followed a scientific model of enquiry to deduce the effect of copayment on effective delivery of health services under capitation contract. Accordingly a philosophical view of positivism was adopted.

\section{Research design}

The prime purpose of the study was to examine the effect of copayment on the indicators of effectiveness. Cross sectional study design which provides a basis for inferring the characteristics of the population from which the sample comes from was employed (Creswell, 2014; Bland, 2001; Mugenda, \& Mugenda, 2003).

\section{Study population, sampling technique and sample size}

Target population was 1152 health facilities contained in a list of the accredited health facilities who had signed capitation contract with National Hospital Insurance Fund as of $1^{\text {st }}$ July 2015. These healthcare facilities were spread across Kenya. Given that the population was diverse, it was classified into seven geographical clusters to facilitate selection of a representative sample. Simple random sampling technique was then used to select a sample of 297 health facilities proportionate to the number of health facilities in each cluster. Sample size was obtained using Yamane's (1967) formula:

$$
n=\frac{N}{1+N e^{2}}
$$

Where $\mathrm{n}$ is the sample size, $\mathrm{N}$ the population size, e is the margin of error. In this study, the margin of error was considered to be $5 \%$. Since the target population was 1152 health facilities, the appropriate sample size was as computed below.

$$
n=\frac{1152}{1+1152 \times(0.05)^{2}} \approx 297
$$

\section{Data collection method}

Structured closed-ended questionnaires were used to collect data. Primary data was collected from the officer incharge of the sampled health facilities while secondary data was obtained from the existing records in the facilities related to capitation practice. A positive response rate of $81 \%$ was attained.

\section{Pilot testing of the instrument}

Pilot study was conducted to test reliability and validity of the research instruments. The test-retest technique was used to test reliability. The ratio of coefficient of variation between the two data sets was close to 1.0. This implied that the research instrument 
was reliable. To test validity of the instruments, the content validity was ascertained by subjecting the research instrument to two experienced hospital administrators practicing under capitation contract. Their feedback was used to improve the research instrument.

\section{Data analysis methods}

Descriptive statistics was used to analyze the variable under study and results presented in tables. The researcher established the relationship between the parametric construct and effectiveness of capitation using regression models. Before running the models, the following diagnostic tests were conducted: Nigelkerke Pseudo R Squared, Hosmer and Lemeshow Test of Goodness of Fit and Omnibus Tests of Model Coefficients.

\section{Results and Discussion}

\section{Descriptive statistics}

The results in Table1 show responses to the question as to whether there is need to charge copayment to capitated members of NHIF. These responses represent both public and private healthcare practitioners where majority $64.9 \%$ supported the need for copayment when practicing under capitation contract scheme.

Table 1: Copayment charge

\begin{tabular}{lcc}
\hline Need for Copayment & Frequency & Percent \\
\hline For & 155 & 64.9 \\
\hline Against & 84 & 35.1
\end{tabular}

\section{Source: Authors}

Table 2 shows Chi-Square test of independence of the variable "need to charge copayment" against type of ownership of the facility. At $5 \%$ level of significance, Pearson Chi-Square value was 4.548 with $p$ value of 0.103 at 2 degrees of freedom. It was therefore evident that there was no association between response on need to charge copayment by capitated members of a health scheme and type of ownership of the health facility.

Table 2: Chi-square tests on copayment against type of ownership

\begin{tabular}{lccc}
\hline Chi-Square Tests & Value & df & Asymp. Sig. (2-sided) \\
\hline Pearson Chi-Square & 4.548 & 2 & .103 \\
\hline Likelihood Ratio & 4.372 & 2 & .112 \\
\hline Linear-by-Linear Association & .002 & 1 & .962 \\
\hline McNemar-Bowker Test &. &. &.${ }^{\mathrm{b}}$ \\
\hline N of Valid Cases & 239 & \\
\hline I cell (16.7\%) has expected count less than 5. The minimum expected count is 4.22.
\end{tabular}

Source: Authors

\section{Regression analysis}

A logit regression model was used to analyze data. Effect of "Need to charge copayment" was analyzed against the three measures of effectiveness; quality, accessibility and affordability of health services. The base category was those against need for copayment. Effect of the moderating variable "Type of Ownership" was analyzed with base category being "profit making facilities". 
Table 3: Regression Analysis on Effect of Copayment on Effective Health Service Delivery

\begin{tabular}{|c|c|c|c|c|c|c|c|c|c|c|c|}
\hline \multirow[t]{2}{*}{ Variable } & \multicolumn{3}{|c|}{ Quality (Model 1) } & \multicolumn{3}{|c|}{ Accessibility (Model 2) } & \multicolumn{5}{|c|}{ Affordability (Model 3) } \\
\hline & B & Sig. & $\begin{array}{l}\text { Exp(B) } \\
\text { (Odds } \\
\text { Ratio) }\end{array}$ & B & Sig. & $\begin{array}{l}\text { Exp(B)(Odds } \\
\text { Ratio) }\end{array}$ & B & Sig. & $\operatorname{Exp}(B)$ & (Odds & Ratio) \\
\hline $\begin{array}{l}\text { Charging } \\
\text { Copayment } \\
\text { (Base } \\
\text { Category= } \\
\text { No) }\end{array}$ & -.070 & .734 & .933 & .107 & .614 & .899 & .156 & .418 & .855 & & \\
\hline $\begin{array}{l}\text { Type of } \\
\text { Ownership } \\
\text { (Base } \\
\text { category = } \\
\text { profit } \\
\text { Making) }\end{array}$ & .827 & .001 & 2.286 & .964 & .001 & 2.623 & .722 & .006 & 2.058 & & \\
\hline Constant & -2.540 & .008 & .079 & -4.639 & .003 & .010 & -1.900 & .026 & .150 & & \\
\hline
\end{tabular}

\section{Source: Author}

Results in Table 3 show that at 5\% level of significance, charging copayment had a negative effect albeit not significant on quality. However, the effect on accessibility and affordability was positive though not significant (all $\mathrm{p}$ values were $>0.05$ ). The indices of quality, accessibility and affordability were $.933, .899$ and .855 respectively. This implied that a unit increment on copayment decreased the index of delivering quality health services by .933 , but increased the indices of delivering accessible and affordable health services by .899 and .855 respectively. Type of ownership had a positive and significant effect on quality, accessibility and affordability with p-values of $0.001,0.001$ and 0.006 respectively. The odds ratios were 2.286, 2.623 and 2.058 for quality, accessibility and affordability respectively. Consequently, non-profit making facilities were $2.286,2.623$ and 2.058 more likely to deliver quality, accessible and affordable health services respectively under capitation contract compared to profit making health facilities.

The regression model for each measure of effectiveness is as shown in equation 3.

$\left[\begin{array}{l}E_{\text {Quality }}=-0.79+.993 x_{1}+2.286 x_{2}+\varepsilon \\ E_{\text {Accessibility }}=0.010+0.891 x_{1}+2.6232 x_{2}+\varepsilon \\ E_{\text {Affordability }}=0.150+0.855 x_{1}+2.058 x_{2}+\varepsilon\end{array}\right]$

Where, $x_{1}, x_{2}$, and $\varepsilon$ respectively represent charging copayment, type of ownership and the error term.

\section{Discussion}

From the descriptive analysis, $64.9 \%$ of healthcare providers in both public and private sector supported charging of copayment whereas, $35 \%$ were against. We postulate that copayment facilitates delivery of effective health services since it is an additional income. In addition, it acts as an incentive to healthcare providers resulting to increased commitment in serving the patients. Healthcare providers are able to improve the availability of drugs and other necessary utilities which lead to delivering of quality health services to the patients (Akashi et al., 2004). According to Gravelle and Siciliani (2008), the providers' concern is that absence of copayment exposes the fund to gross misuse by members and excessive demands of expensive treatments, factors that affected negatively affordability from providers' perspective hence inability to avail the needed resources such as drugs.

Regression models indicate that adding a copayment charge to patients covered under capitation scheme would have a positive albeit statistically not significant effect on quality of healthcare at $5 \%$ level of significance with a quality index of .073 which implies increase in the odds of providing the needed serve to the patient by .073 . This can be explained by the fact that the healthcare provider becomes economically empowered hence can afford to offer quality services. The study findings are inconsistent with Winkelmann (2004) study who examined the impact of copayment for prescribed drugs, which had been increased by up to $200 \%$ through reforms in German. The study findings were that the number of visits to the doctors decreased by $15 \%$. It also concurs with study done by 
Kipp et al. (2001) in Uganda where a copayment of between 50 to 500 Uganda shillings (US\$0.05-0.5) for each outpatient consultation was introduced. The results showed that there was a decrease in overall out-patients visits. Augurzky et al. (2006) argue that copayments paid by members of a capitation scheme gives the healthcare providers extra ability to provide affordable, quality and accessible medical services to the insured members. Varela and Timofte (2011), further extend this view by observing that copayment is often a small fraction of the actual cost of the health services provided. However, the underlying philosophy is to reduce unnecessary utilization of healthcare resources by having the members cost-share in financing medical-care. The saved resources and the additional income go towards improving delivery of effective health services.

Regression results on effect of copayment on delivering affordable and accessible health services under capitation scheme showed positive effect though statistically not significant at 5\% level of significance. The indices were 79.399 and 4.349 respectively. The Kenyan capitation scheme for healthcare services allocates and pays the providers a fixed payment of Kenya shilling 100 (US\$1.0) per member per month with no adjustments to any risks such as patient needing expensive medical examinations or drugs. In exchange for the fixed payment per enrolled member, the healthcare provider commits to absorb the costs associated with unlimited healthcare services the member may require and to benefit from any profits thereof. The money paid inform of copayments to a healthcare provider is an additional income. Accordingly, this additional dollar would increase the likelihood of affordability to offer the needed healthcare by 79.399 and additionally increase the likelihood of making available resources such as drug by 4.349 which patients can access.

\section{Conclusions}

Delivery of health services under capitation contract is intricate especially where there is no risk adjustment of treatments of patients with chronic conditions who repeatedly visit the service provider, extra payment for expensive procedures or prescribed drugs and where there is no limit as to the number of consultations a capitated member can consult a healthcare provider within the contract period. The system is hence open to misuse by the insured member who often demand expensive prescriptions. While it is the patients' right to be treated to satisfaction, it is also healthcare providers' right to guard against misuse of health resources which compromise delivery of quality services and affordability of service delivery. In view of the health seeking behavior by members covered under capitation scheme, charging a small fraction of the actual cost of the health services provided in form of a copayment per consultation helps to reduce the unnecessary utilization of resources. We postulate that copayment facilitates delivery of effective health services since it serves as an additional income that enhances ability to deliver affordable services. In addition, it acts as an incentive to healthcare providers resulting to increased commitment in serving the patients.

Considering that copayment is an out-of-pocket payment and can act as a barrier to access medical services by needy patients, this study recommends that an optimal copayment should be determined that is high enough to prevent unnecessary utilization of healthcare resources but low enough to enable access to healthcare by the needy insured members. In addition, this study has contributed empirical data on effect of copayment on delivery of effective health service under capitation contract from health providers' perspective which is the supply side. Further studies can be undertaken that focus on demand side of healthcare.

\section{References}

Akashi, H., Yamada, T., Huot, E., Kanal, K., \& Sugimodo, T. (2004). User fees at public hospital in Cambodia: Effects on hospital performance and provider attitudes. Social Sciences and Medicines, 58(3), 553-564

Allard, M., Jelovac, I., \& Léger, P. T. (2014). Payment mechanism and GP self- selection: Capitation versus fee for service. International Journal of Health Care Finance and Economics, 14(2), 143-160

Ataguba, J. E., \& Akazili, J. (2010). Health care financing in South Africa: moving towards universal coverage.Continuing Medical Education, 28(2), 74-78.

Augurzky, B., Bauer, T. K., \& Schaffner, S. (2006). Copayments in the German Health System - Do They Work? RWI Discussion Papers, (2290). http://doi.org/10.2139/ssrn.928914

Babazono, A., Miyazaki, M., \& Une, H. (2004). A study on a reduction in visits to physicians after introduction of 30 percent copayments in theEmployee Health Insurance in Japan. Indust Health, 42, 50-56.

Balarajan, Y., Selvaraj, S., \& Subramanian, S.V. (2011). Health care and equity in India. The Lacencet Journal 377(9764),505-15

Bland, M. (2001). An Introduction to Medical Statistics. (3rd ed.) Oxford, Oxford University Press.

Ciemens, E. L. (2004). The effect of parity-induced copayment reductions on adolescent utilization of substance use services. Journal of Studies in Alcohol and Drugs, 65(6), 731-735.

Chen, L. C., Schafheutle, E. I, \& Res, M. (2009). The impact of nonreferral outpatient copayment on medical care utilization and expenditures in Taiwan, Research in Social and Administrative Pharmacy, 5(3), 211-224.

Creswell, J.W. (2014). Research design: Qualitative, Quantitative and Mixed Method Approaches (4th ed.). New Dalhi: Sage Publishers ltd.

El-Khoury, M., Hatt, L., Gandaho, T. (2012). User fee exemptions and equity in access to caesarean sections: an analysis of patient survey data in Mali. International Journal Equity Health, 11, 49-51

Fama, E. F. (1980). Agency Problems and the Theory of the Firm. Journal of Political Economy, 88(2), $288-307$. 
Goldman, D. P., Joyce, G. F. \& Zheng, Y.(2007). Prescription drug cost - sharing : associations with medication and medical utilization and spending and health. JAMA, 298, 61-69.

Gravelle, H., \& Siciliani, L.(2008). Optimal quality, waits and charges in health insurance. Journal of Health Economics, 27(3), 663674.

Hooda, S. K. (2017). Out-of-pocket Payments for Healthcare in India: Who Have Affected the Most and Why? Journal of Health Management, 19(1) 1-15

Horowitz, J. L. (1997). Contact capitation: an alternative for specialist capitation. Healthcare Financial Management Journal of the Healthcare Financial Management Association, 51, 54-55.

Hunte, P., \& Sultana, F. (1992) Health Seeking Behavior and the Meaning of Medications in Balochistan, Pakistan. Social Science\& Medicine, 34, 1385-1397.

Kipp, W., Kamugisha, J., Jacobs, P., Burnham G., \& Rubaale, T. (2001). User fees, health staff incentives, and service utilization in Kabarole District, Uganda. Bulletin of the World Health Organization 79(11), 1032- 1037.

Kipyegon, K., \& Nyarombe, F. (2015). An Investigation of the Factors Affecting Capitation Programme in Provision of the Health Care Services: a Case of Nairobi County Accredited Health Facilities, International Journal of Business and Management Invention 4(1), 33-53.

Mugenda, O., \& Mugenda, A. (2003). Research Methods: Quantitative and Qualitative Approaches. Nairobi: Acts Press

Nabyonga, J., Desmet, M., Karamagi, H., Kadama, P.Y., \& Omaswa, F. G. (2005). Abolition of cost-sharing is pro-poor: evidence from Uganda. Health Policy and planning, 20(2), $100-108$

Newhouse, J. P. (1996). Reimbursing health plans and health providers: Efficiency in production versus selection. Journal of Economic Literature, 34(3), 1236-1263 Wagstaff.

Orem, J.N., Mugisha, F., Kirunga, C., Macq, J. \& Criel, B. (2011). Abolition of user fees: The Uganda paradox. Health Policy Plann, $26,41-56$.

Purkayastha, S., Manolova, T. S., \&Edelman, L. F. (2012). Diversification and Performance in Developed and Emerging Market Contexts: A Review of the Literature. International Journal of Management Reviews, 14, 18-38.

Saksena, P., \& Antunes, A.I. F. (2011). Mutual health insurance in Rwanda: vidence on access to care and financial risk protection. Health Policy, 99(3), 203-209

Selby, J. V., Fireman, B. H., \& Swain, B. E. (1996). Effect of a copayment on use of the emergency department in an HMO. New England Journal of Medicine, 334, 10

Shapiro, Ware, \& Sherbourne (1986). Effects of cost sharing on seeking care for serious and minor symptom: Results of a randomized controlled trial. Annals of Internal Medicine Journal, 104, 246- 251.

Varela, D. \& Timofte, A., (2011). The ocial cot of hospital waiting list and the case for copayment: Evidence from Galicia. The USV Annals of Economics and Public Administration, 11(1), 18-26.

WHO (2010). World Health Report: Health Systems Financing: key to Universal Coverage. Geneva.

Winkelmann, R. (2004). Co-payments for prescription drugs and the demand for doctor visits - Evidence from a natural experiment. Health Economics, 13(11), 1081-1089.

Witter, S., Dieng, T., Mbengue, D., Moreira, I., De Brouwere, V. (2010). The national free delivery and caesarean policy in Senegal: evaluating process and outcomes. Health Policy Plan, 25, 384-92. 